Foldes, F. F., Molloy, R., McNall, P. G., and Koukal, L. R. (1960). F. Amer. med. Ass., 172, 1493.

Geddes, I. C. (1958). Anaesthesia, 13, 200.

Holmes, C. M. (1963). Lancet, 1, 245.

Hooper, R. L. (1964). Canad. Anaesth. Soc. F., 11, 247.

Macgregor, J. D. (1960). Lancet, 1, 528.

Moore, D. C., and Bridenbaugh, L. D. (1960). F. Amer. med. Ass., 174, 842 .
Morrison, J. T. (1931). Brit. F. Surg., 18, 641.

Sadove, M. S., Wyant, G. M., Gittelson, L. A., and Kretchmer, H. E.

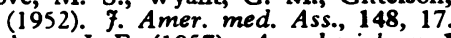

Steinhaus, J. E. (1957). Anesthesiology, 18, 275.

Stewart, D. M., Rogers, W. P., Mahaffey, J. E., Witherspoon, S., and Woods, E. F. (1963). Ibid., 24, 620.

Sung, C-Y., and Truant, A. P. (1954). F. Pharmacol. exp. Ther., 112, 432.

\title{
Regional Anaesthesia by the Intravenous Route
}

\author{
CHARLES SORBIE,* M.B., F.R.C.S.ED.; PESI CHACHA, † M.B., F.R.C.S.ED., F.R.C.S.GLASG.
}

Brit. med. F., 1965, 1, 957-960

A satisfactory technique for the production of intravenous regional anaesthesia was first described by Bier (1908, 1909, 1910) but, surprisingly, it did not achieve any measure of popularity. It has recently been revived by Holmes (1963). The technique is simple and it provides perfect anaesthesia for short procedures to the distal parts of the limbs. It is particularly suitable for a busy casualty department, as no premedication or other preparation is necessary, and the patient is ready to leave hospital immediately after completion of the operation.

The method has been used on 128 patients without ill-effect and with few failures. The technique is described below, and an attempt made to explain the mechanism by which anaesthesia is produced.

\section{Method}

The patient lies on an operating-table or trolley. No premedication is required. A sphygmomanometer cuff is wrapped round the upper part of the arm. It is inflated until venous distension is produced. The back of the hand is cleaned with antiseptic solution and a Gordh needle is inserted into a dorsal vein. The sphygmomanometer cuff is then deflated and the arm is elevated to allow blood to flow out of the limb. If complete exsanguination is required for the operation an Esmarch bandage can be used. After about one minute the cuff is reinflated to a point well above arterial pressure, usually about $200-250 \mathrm{~mm}$. $\mathrm{Hg}$, and $20-40 \mathrm{ml}$. of $0.5 \%$ plain lignocaine, depending on the size of the limb, is then injected through the Gordh needle.

When anaesthesia is complete a second sphygmomanometer cuff is applied around the arm immediately distal to the first cuff. It is also inflated to above arterial pressure. The proximal cuff is then removed and the needle is withdrawn from the vein. It is necessary to use two tourniquets, as the tissues under the first tourniquet are not anaesthetized.

As the anaesthetic is injected the patient may experience a feeling of warmth in the arm or hand, followed by tingling in the fingers. Blotchy discoloration of the skin may be seen over small areas near superficial veins. After an interval of three to five minutes patches of numbness appear, and these gradually spread until the whole forearm is anaesthetic.

The technique for producing anaesthesia of the leg is similar to that for the arm except that $40-80 \mathrm{ml}$. of lignocaine is required. The veins on the dorsum of the foot are used for the injection and the tourniquets are applied to the thigh.

\footnotetext{
* Senior Orthopaedic Registrar, Western Infirmary, Glasgow.

† Orthopaedic Registrar, Western Infirmary, Glasgow.
}

When the tourniquet is removed at the end of the operation, sensation is restored rapidly, usually in about five minutes.

\section{Results}

The ages of the 128 patients who had regional anaesthesia for surgical procedures (Table I) ranged from 12 to 86 years.

Anaesthesia was considered to be successful when the patient did not experience any discomfort at the site of operation during the surgical procedure.

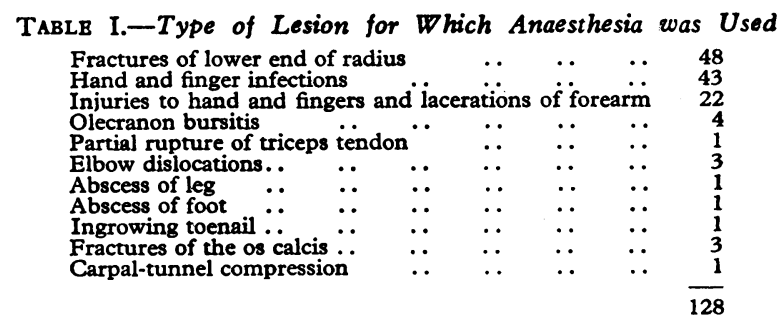

Fifteen patients complained of a greater or lesser degree of discomfort at the operation site. Ten of these required additional anaesthesia for the completion of the operation. In addition, 10 patients complained of pain under the tourniquet varying from mild to severe. In nine, only one tourniquet had been used. The remaining patient, a 15-year-old boy, had two tourniquets applied, but his operation lasted 45 minutes. Tourniquet discomfort has been almost eliminated by the use of two tourniquets.

It is evident (Tables II and III) that a much higher percentage of unsuccessful anaesthetics occurred with cubital injections

TABLE II.-Mean Time for Complete Anaesthesia was Calculated Only

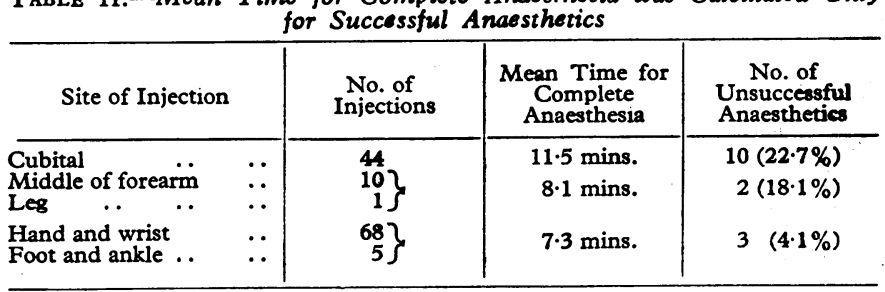

$$
\begin{aligned}
& \text { TABLB III.-Unsuccessful Anaesthetics } \\
& \text { Site of Injection } \\
& \text { Type of Lesion }
\end{aligned}
$$

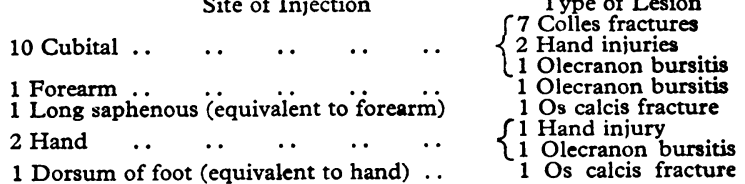


$(22.7 \%)$ than with hand injections $(4.1 \%)$; also that this method of anaesthesia is not satisfactory for lesions around the back of the elbow (such as olecranon bursitis). Only two lesions out of five in this region had adequate anaesthesia. Reasons for these failures are advanced below when discussing the mechanism of anaesthesia.

\section{Discussion}

Three questions have to be answered in attempting to explain the anaesthesia produced by this technique. At what neural level is the anaesthesia produced ? Does ischaemia make any contribution to the anaesthesia? Why does the anaesthesia disappear so rapidly after the tourniquet is removed ?

Bier (1910) studied the diffusion of a " coloured substance" into the tissues when it was injected into an arm vein below the level of a tourniquet. Freshly amputated and cadaveric limbs were used. He concluded that the substance dispersed rapidly to all parts, including the main nerve trunks. Similarly when lignocaine is injected into a hand vein it will spread through the venous system of the forearm. The dispersion of anaesthetic in favour of the nerve trunks is facilitated by their rich vascular systems and the absence of valves in the small veins, less than $2 \mathrm{~mm}$. in diameter (Gray's Anatomy, 1954), which emerge at intervals along the course of the main nerves.

Dispersion of the anaesthetic solution is most rapid and complete when a hand vein is used for the injection. When a cubital vein is used (Fig. 1) retrograde flow of the solution is prevented while the valves within the vein remain competent. The ability of these valves to withstand considerable pressure was reflected in the occurrence of dizziness in several patients during cubital-vein injection, from lignocaine escaping under pressure via humeral veins into the general circulation. In addition, these patients had unsatisfactory anaesthesia.

When only one tourniquet is used for this technique an irregular band of unanaesthetized skin is found immediately distal to the tourniquet. In addition, the areas of skin supplied by the intercosto-brachial, the lower lateral, and the posterior cutaneous nerves of the arm (Fig. 2) are poorly anaesthetized. It is probable that these nerves, and other small cutaneous nerves, have few venules emerging from them when they have passed beyond the tourniquet, as they are nearing their terminations. Consequently anaesthetic solution in the venous system would have difficulty in making an intimate contact with their axons.

To confirm that anaesthesia occurs primarily at the level of main nerve trunks-that is, where the nerve is large enough to have a vascular network within its sheath, two subjects had regional anaesthesia produced between two tourniquets. In each subject one tourniquet was placed around the upper arm and the other at the level of the wrist (Fig. 3). Then $20 \mathrm{ml}$. of $0.5 \%$ lignocaine was injected into a forearm vein immediately above the distal tourniquet. Both subjects developed complete anaesthesia of the arm and hand which spread with a definite nerve-trunk pattern. In one subject the lateral side of the forearm was first to lose sensation, followed in succession by the whole radial, ulnar, and median areas. In the other subject a similar pattern of anaesthesia was observed except that the ulnar area was affected before the radial.

With this technique, ischaemia may contribute to anaesthesia when 30 minutes have elapsed after application of the tourniquet. Anaesthesia of a limb from ischaemia alone has a different pattern of onset to that following lignocaine injection and is considerably slower in development. When we subjected our arms to total ischaemia, anaesthesia was not complete for 40 minutes. Sensation was lost first from the finger-tips, and gradually the anaesthetic area extended more or less evenly up the arm. Motor power was lost in a similar fashion, extensors being affected sooner than flexors. Nerve-conduction tests were performed on six subjects. In three the arm to be examined was made ischaemic until all sensation and motor power were absent. In the remaining three regional anaesthesia was produced in the routine way. Coaxial needle
FiG. 1.-Phlebograms of forearm under tourniquet using Hypaque $45 \%$, (a) 3 seconds and (b) 15 seconds after injection into a hand vein. (c) 3 seconds and (d) 18 seconds after injection into a cubital vein. 
electrodes were inserted into the first dorsal interosseus muscle and the ulnar nerve was stimulated at the elbow. The time from stimulus to response at the first dorsal interosseus was recorded at regular intervals until the response disappeared. There was a difference in the pattern of nerve-conduction loss in the

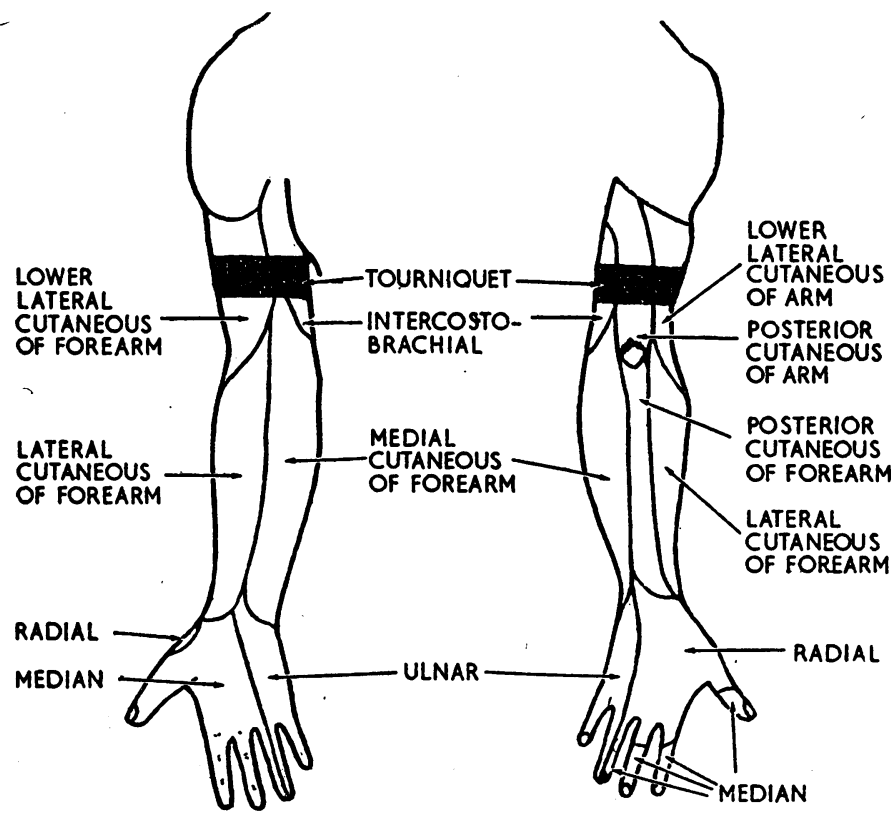

FIG. 2.-Cutaneous-nerve supply to the arm, anterior and posterior.

ischaemic limb as compared with the anaesthetic limb, which confirmed that anaesthesia was not due to ischaemia alone (Fig. 4). The average increase in the conduction-time interval prior to complete blockage of conduction was $26.6 \%$ with pure ischaemia after a time of 30 minutes, and $85.3 \%$ with anaesthetic block after only 17.3 minutes (Fig. 5). When anaesthesia is complete it is clearly not possible to determine by which means it is being maintained. It is probable, however, that as time passes the anaesthetic solution will leak through bone veins into the general circulation and anaesthesia will be maintained to some extent by ischaemia.

Anaesthesia starts and is initially maintained by the gradual diffusion of lignocaine from venules direct on to nerve fibres.

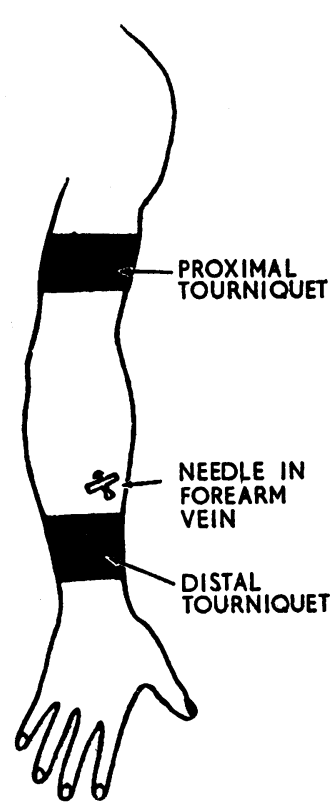

FIG. 3.-Position of tourniquets and needle to determine level of anaesthesia.
Minor toxic effects consist of ringing in the ears and faintness. Major toxic effects are hypotension, convulsions, and respiratory depression. Minor effects may be encountered when the tourniquet is released at the end of the procedure. At this time any lignocaine remaining in the veins will enter the general circulation. "Buzzing" in the ears or faintness may also be felt while injecting into a cubital vein, whose competent valves may allow enough pressure to be built up within the vein for lignocaine to escape, through humeral veins, into the general circulation.

It is obvious that this method of anaesthesia should be used only in a hospital, with the patient lying on an operating-table or trolley that can be tilted and with an anaesthetic machine available.

Bromage and Robson (1961) have defined the upper dosage limits of lignocaine in healthy individuals, for the avoidance of toxicity, at $0.3 \mathrm{mg} . / \mathrm{kg}$. of body weight for 30 minutes, or a blood concentration of $10 \mu \mathrm{g} . / \mathrm{ml}$. This represents about 20 $\mathrm{mg} . / \mathrm{min}$. for an average $(70 \mathrm{~kg}$.) man.

Foldes et al. (1960) observed the effects of injecting lignocaine at a rate of $0.5 \mathrm{mg} . / \mathrm{kg} . / \mathrm{min}$. None of their subjects tolerated the infusion for more than 18 minutes, by which time $600 \mathrm{mg}$. might have been given. The maximum safe dose has been calculated to be in the region of $500 \mathrm{mg}$.

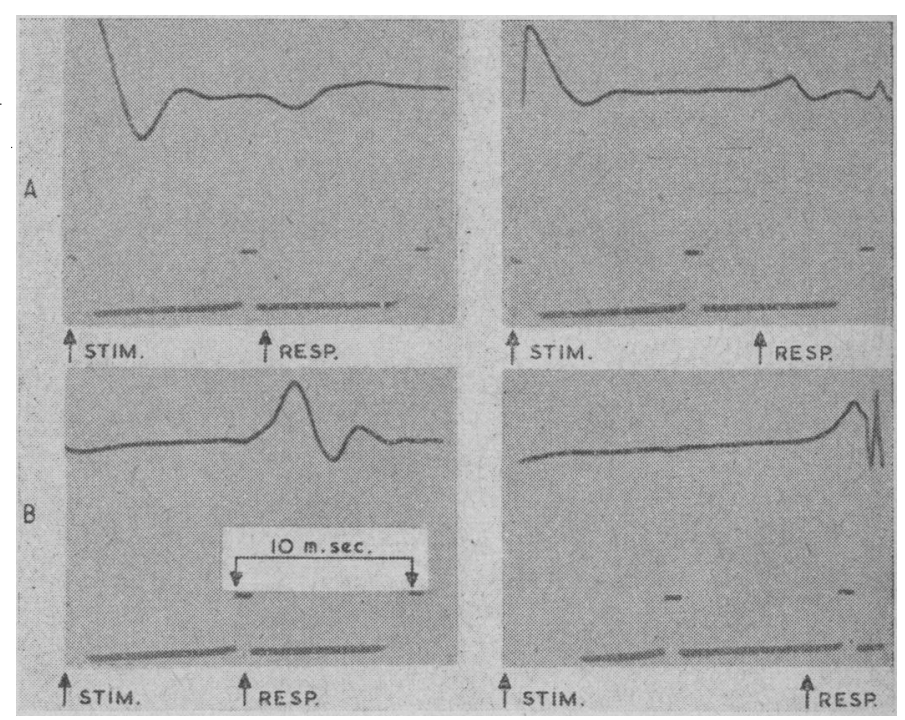

FIG. 4.-(a) Ischaemic limb. (b) Anaesthetic limb. The traces on the left are normal conduction tests for stimulation of the ulnar nerve at the elbow and recording the response at the first dorsal interosseus. The traces on the right were made immediately prior to cessation of conduction:

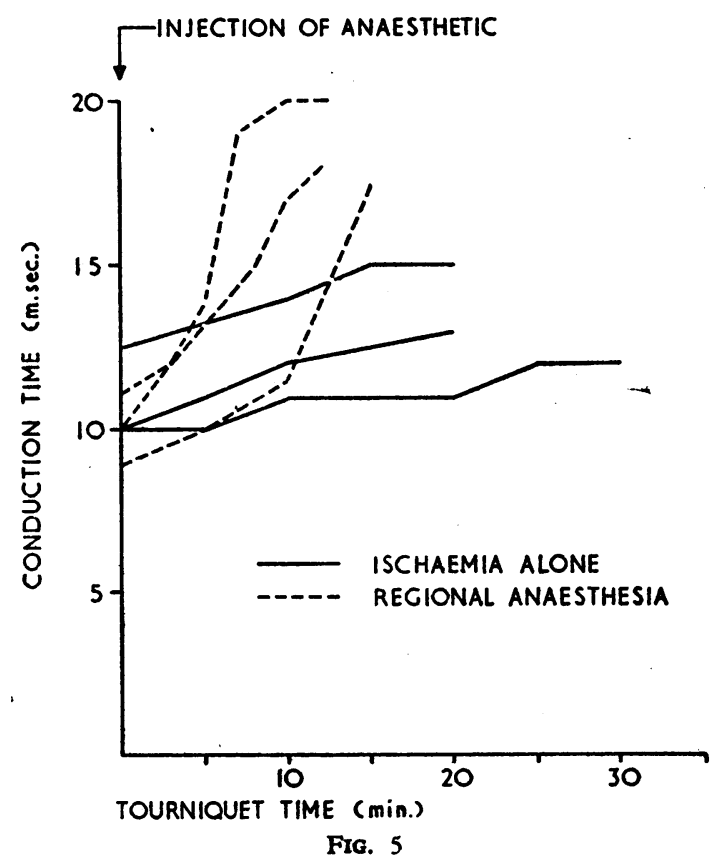

FrG. 5 
The patients in this series were not weighed before anaesthesia, and therefore the dosage was not accurately determined. For forearm anaesthesia 100-200 mg. was given, and for the leg $200-400 \mathrm{mg}$. The amount was related to the size of the patient, but never exceeded the total safe dose.

\section{Conclusions}

The effectiveness of this method in the production of anaesthesia cannot be doubted. Only 10 patients out of 128 in this series required additional anaesthesia for the completion of a surgical procedure. The reasons for failure in these patients have already been advanced, and it is probable that the method as described will be completely successful if the following points are remembered:(1) the anaesthetic solution should always be injected into a vein on the back of the hand-if this is not possible the most distal forearm vein should be chosen ; and (2) it is unreliable for procedures in the territories of the intercosto-brachial, lower lateral cutaneous, and posterior cutaneous nerves of the arm.

\section{Summary}

Further experience in the value, effectiveness, and safety of intravenous regional anaesthesia is presented. This method was used by house-surgeons working in a busy casualty department to treat a wide variety of conditions affecting the distal parts of the limbs. It was most often used in the treatment of Colles fractures and hand and finger infections. Successful anaesthesia was achieved in 113 out of 128 patients on whom this method was employed.

An attempt is made to explain the mode of action of a local anaesthetic when injected into the venous system of an isolated limb segment. Rapid dispersion of anaesthetic solution occurs when distal veins are used. Direct contact with main nervetrunk fibres is facilitated by the permeability of venules and the richness of the vasa nervorum.

Comment is made on the rapid return of normal sensation when the tourniquet is removed at the end of the procedure and on the role of ischaemia in the production of anaesthesia by this technique. Nerve-conduction tests demonstrated that ischaemia does not, initially, contribute to anaesthesia.

No serious toxic reactions were encountered using $0.5 \%$ plain lignocaine. The dosage did not exceed $200 \mathrm{mg}$. for the arm and $400 \mathrm{mg}$. for the leg.

We are indebted to Professor Roland Barnes for his helpful criticism in the preparation of this paper and to Mr. R. LoudenBrown for the illustrations.

\section{REFERENCES}

Bier, A. (1908), Arch. klin. Chir., 86, 1007. (1909) Münch med. Wschr. 1, 589. (1909). Munch. med. W schr.,

Bromage, P. R., and Robson, J. G. (1961). Anaesthesia, 16, 461.

Foldes, F. F., Molloy, R., McNall, P. G., and Koukal, L. R. (1960). 7. Amer. med. Ass., $172,1493$.

Gray's Anatomy, 1954, 31 st ed., p. 687. Longmans, Green, London.

Holmes, C. McK. (1963). Lancet, 1, 245

Sung, C. Y., and Truant, A. P. (1954). F. Pharmacol. exp. Ther., 112, 432 .

\section{The Family History of Diabetes}

\section{Report of a Working Party* Appointed by the College of General Practitioners}

Brit. med. 7., 1965, 1, 960-962

Much has been written on the hereditary factors of diabetes mellitus (Harris, 1950 ; Steinberg, 1959 ; Johnson, 1961; Nilsson, 1962), but there is still doubt about their significance. This is because diabetes is a common disease, making the chance association of cases in the same family reasonably probable. The variable age of onset and the marked variation in severity of the disease are also factors which contribute to the difficulties of assembling the facts. The early work of Pincus and White (1933) established that there was a higher prevalence of the disease among relatives compared with a control population. Many later reports (Harris, 1950 ; Steinberg and Wilder, 1952 ; Thompson and Watson, 1952) have lacked control data. Penrose (1953) has stressed that in the analysis of such material care must be taken to match the findings in the parents, siblings, and offspring of the propositi with those in the control group of similar age, and quotes the work of Doll and Buch (1950) on the inheritance of peptic ulcer as an ideal example of the method. The recent large-scale diabetes survey in Birmingham (Report from the College of General Practitioners, 1962) has

- Members of the Working Party: Dr. J. M. Malins, Dr. M. G. FitzGerald, and Dr. Gaddie, of the General Hospital, Birmingham ; Dr. K. W. Cross, of the Department of Medical Statistics, Birmingham University ; Miss Mary Wall of of Medical Statistics, Birmingham University; Miss Mary Wall, of the Birmingham Regional Hospital Board ; and Dr. A. J. Allen, Dr. Amy M. Allen, Dr. D. L. Crombie, Dr. L. S. Gathergood, Dr. C. M. Green, Dr. R. H. Morgan, Dr. A. J. Pearce, Dr. L. A. Pike, Dr. R. J. F. H. Pinsen
Thorpe, of the College of General Practitioners.

Dr. D. L. Crombie, Dr. M. G. FitzGerald, and Miss Mary Wall were the recorders. provided the opportunity for collecting control data about the prevalence of known diabetes in the general population, and this has been compared with the findings in newly diagnosed diabetics at the hospital clinic in the way Penrose has suggested.

\section{Method}

The propositi were 1,307 patients with clinical diabetes who attended the hospital clinic, at diagnosis, during 1961 and 1962. Diabetes was diagnosed on clinical grounds, and confirmed by finding hyperglycaemia. This was defined as a capillary blood glucose in excess of $180 \mathrm{mg} . / 100 \mathrm{ml}$. two hours after the midday meal. Asymptomatic cases where a glucosetolerance test was required for diagnosis have been excluded if the fasting blood glucose was less than $130 \mathrm{mg} . / 100 \mathrm{ml}$. The non-diabetic control was a group of 859 persons taken at random from the lists of a number of family doctors. They had all tested their urine with Clinistix, and had not found glycosuria (Report from the College of General Practitioners, 1962). In both the diabetic and control groups inquiries were made, on the first visit, about the known family history of diabetes in the parents, siblings, and offspring alive or dead. The total number of siblings and offspring was also recorded.

Prevalence rates for known diabetes, at different ages, have been estimated from 18,532 people who constituted the population of 10 practices in or around Birmingham. 